\title{
DETERMINAÇÃO DA MATURIDADE FISIOLÓGICA DE FRUTOS DE MARACUJAZEIRO-AMARELO COLHIDOS NA REGIÃO NORTE DO ESTADO DO RIO DE JANEIRO, BRASIL ${ }^{1}$
}

\author{
THAIS VIANNA-SILVA², RENATA VIANNA LIMA³, INGA GONÇALVES DE AZEVEDO ${ }^{4}$, \\ RAUL CASTRO CARRIELO ROSA ${ }^{5}$, MAXIMILIANO SILVA DE SOUZA ${ }^{6}$, \\ JURANDI GONÇALVES DE OLIVEIRA ${ }^{7}$
}

RESUMO-O trabalho teve como objetivo determinar o ponto de maturidade fisiológica dos frutos de maracujazeiro-amarelo produzidos na região Norte Fluminense, na tentativa de se antecipar o ponto de colheita dos frutos, visando à qualidade e ao aumento da vida de prateleira dos mesmos. Os frutos foram colhidos em três períodos diferentes. A colheita 1 foi realizada aos 45 dias após a antese (daa); a colheita 2 aos 54 daa e a colheita 3 aos 63 daa. Após cada colheita, os frutos foram lavados, secos e divididos em dois lotes para avaliação. O primeiro lote foi avaliado imediatamente após a colheita, e o segundo foi armazenado em câmara ( $23 \pm 3^{\circ} \mathrm{C}$ e $85 \pm 8 \%$ UR). Os frutos foram analisados periodicamente, a cada 3 dias, quanto aos seguintes atributos de qualidade: coloração e espessura da casca, rendimento de suco e teores de sólidos solúveis (SS) e acidez titulável (AT). Os resultados indicaram que o tempo de desenvolvimento do fruto de maracujazeiro-amarelo, dentro do período de 45 a 63 daa, influenciou na qualidade do fruto colhido na região. Para as condições deste trabalho, o ponto ideal de colheita foi aos 63 daa, podendo, também, ser colhido a partir do $54^{\circ}$ daa, porém com perda de cerca de 21,0 \% no rendimento de suco. Verificou-se, também, que durante a fase de amadurecimento, a manutenção dos frutos na planta retarda a evolução da coloração, bem como a redução na espessura da casca do fruto, em comparação ao colhido e armazenado.

Termos para Indexação: desenvolvimento, maracujá, Passiflora edulis Sims., qualidade.

\section{DETERMINATION OF THE PHYSIOLOGYC MATURITY OF YELLOW PASSION FRUIT HARVESTED IN THE NORTH OF THE STATE OF RIO DE JANEIRO, BRAZIL}

\begin{abstract}
This work aimed to determine the physiologic maturity of yellow passion-fruit produced in the North of Fluminense region, with the aim of advancing the point of fruit harvest and improving the quality and shelf life of the fruit. The fruit were harvested in three different periods. Harvest 1 occurred during the 45 day after anthesis (daa); harvest 2 from 54 daa and harvest 3 from 63 daa. After each harvest, the fruit were washed, dried and separated in two groups for evaluation. The first group was evaluated immediately after the harvest, and the second was stored in a chamber at room temperature $\left(23 \pm 3^{\circ} \mathrm{C}\right.$ and $\left.\mathrm{RH} 85 \pm 8 \%\right)$. The fruit were evaluated periodically in interval of 3 days, for the following quality attributes: skin color and thickness, juice yield, soluble solids (SS) and titratable acidity (TA) contents. Results indicate that the time of yellow passion-fruit development, between the periods of 45 to 63 daa, influenced the fruit quality of the harvest in the region. For the conditions of this study, the optimal time of harvest was at 63 daa, although fruit may however, be harvested by 54 daa, with loss around $21.0 \%$ of the juice yield. Also, during the ripening stages of the passion-fruit, it was seen that the attached fruit show a delay in color progress and reduction in the thickness of the skin, when compared with harvested and stocked fruit.
\end{abstract}

Index terms: development, passion fruit, Passiflora edulis Sims., quality.

\footnotetext{
${ }^{1}$ (Trabalho 027-09). Recebido em: 10-01-2009. Aceito para publicação em: 10-12-2009.Parte da tese de doutorado do primeiro autor que teve suporte financeiro da CAPES e FAPERJ.

${ }^{2}$ DSc., Instituto Federal do Espírito Santo/Campus de Alegre. Alegre-ES, 29500-000. thais-vianna@hotmail.com

${ }^{3}$ MSc., Universidade Estadual do Norte Fluminense Darcy Ribeiro - UENF. Campos dos Goytacazes,-RJ, 28013-602. renataalegre@hotmail.com

${ }^{4}$ MSc., UENF. Campos dos Goytacazes-RJ, 28013-602.inga@uenf.br

${ }^{5}$ DSc., UENF. Campos dos Goytacazes-RJ, 28013-602. carrielo@uenf.br

${ }^{6}$ MSc., Escola Técnica Estadual Agrícola Antonio Sarlo - Rede FAETEC, Campos dos Goytacazes-RJ. 28000-000. maxbji@hotmail.com

${ }^{7}$ DSc., Professor Associado UENF. Campos dos Goytacazes-RJ, 28013-602. jugo@uenf.br *Autor para correspondência.
} 


\section{INTRODUÇÃO}

Nos últimos anos, o Brasil tem-se destacado como principal produtor e consumidor de maracujá, e entre as espécies de passifloráceas economicamente importantes para o País destaca-se o maracujazeiroamarelo (Passiflora edulis Sims.) (Bernacci et al., 2008), que é considerado o maracujazeiro mais plantado e de maior comercialização de norte a sul do Brasil (Aguiar \& Santos, 2001; Durigan et al., 2004).

O fruto do maracujazeiro-amarelo é bastante consumido, pois seu suco possui alto valor nutritivo e excelentes características organolépticas. No entanto, ele é um dos frutos tropicais de mais difícil conservação. Sob condições de ambiente natural, seu aspecto visual fica comprometido em apenas três a sete dias, devido à intensa atividade respiratória e à excessiva perda de água pela transpiração. Estes processos aceleram o murchamento (enrugamento) da casca, diminuindo a qualidade do fruto e, consequentemente, depreciando seu valor comercial (Arjona et al., 1992; Marchi et al., 2000; Durigan et al., 2004).

Tradicionalmente, a colheita do maracujáamarelo favorece a reduzida vida útil dos frutos, pois ela é realizada após a abscisão natural dos frutos, com a catação dos mesmos no chão ou presos nas ramagens da planta (Arjona et al., 1992; Durigan, 1998; Marchi et al., 2000). Tentando-se melhorar a conservação pós-colheita do maracujá e a crescente demanda por frutos de melhor aspecto visual, compensada aos produtores por melhores preços, este tipo de colheita está sendo mudada. Atualmente, os produtores têm colhido frutos em estádio de maturação mais precoce, permitindo estender o tempo de prateleira dos mesmos (Shiomi et al., 1996; Durigan et al., 2004).

O reconhecimento do início do amadurecimento dos frutos do maracujazeiro-amarelo ou o seu período de maturidade fisiológica é fundamental para a antecipação e a determinação do ponto de colheita, sem que ocorram perdas na qualidade. Neste caso, é necessária a realização de análises físicas e químicas ao longo do período de maturação, para a verificação dos atributos de qualidade e, consequentemente, a avaliação de seu amadurecimento (Watada et al., 1984; Kluge et al., 2002; Chitarra \& Chitarra, 2005).

Este trabalho teve como objetivo avaliar alguns dos principais atributos de qualidade de frutos de maracujazeiro-amarelo para a determinação de seu ponto de maturidade fisiológica (MF), quando produzidos na região norte do Estado do Rio de Janeiro.

\section{MATERIAL E MÉTODOS}

O experimento foi conduzido em pomar de maracujazeiro-amarelo ( $P$. edulis f. flavicarpa Degener), no município de Campos do Goytacazes-RJ, com as coordenadas geográficas de $21^{\circ} 42^{\prime} 49^{\prime \prime}$ de latitude sul e $41^{\circ} 20^{\prime} 33^{\prime \prime}$ de longitude oeste.

A partir da marcação dos botões florais, os frutos foram colhidos em três períodos diferentes. A primeira colheita (colheita 1) foi realizada aos 45 dias após a antese (daa), a segunda (colheita 2) aconteceu aos 54 daa e a terceira (colheita 3), aos 63 daa.

$\mathrm{O}$ experimento foi conduzido segundo um delineamento inteiramente casualizado (DIC), em esquema fatorial $3 \times 4$, sendo três épocas de colheita e quatro tempos de avaliação (0; 3; 6 e 9 dias) após a colheita, com três repetições. Os resultados foram analisados quanto à variância e às médias por regressão.

Após cada colheita, os frutos foram levados para o Setor de Fisiologia Vegetal (LMGV) da Universidade Estadual do Norte Fluminense Darcy Ribeiro (UENF), onde eram limpos e armazenados sob condições controladas $\left(23 \pm 3^{\circ} \mathrm{C}\right.$ e $85 \pm 8 \%$ UR). As medições da coloração do fruto foram realizadas utilizando um colorímetro portátil (Chroma Meter modelo CR-300, Minolta), registrando-se três leituras em pontos equidistantes, na região equatorial do fruto, utilizando-se do valor médio para os seguintes parâmetros de cor: luminosidade e ângulo hue (McGuire, 1992). O teor de sólidos solúveis (SS) foi determinado em refratômetro portátil (Atago N1), e os resultados, expressos em ${ }^{\circ}$ Brix. A acidez titulável (AT) foi determinada através de titulação de amostra do suco com $\mathrm{NaOH}$ a 0,01 M, conforme metodologia indicada pelo Zenebon (2008), com os resultados expressos em percentagem de ácido cítrico.

\section{RESULTADOS E DISCUSSÃO}

Os resultados mostram que a luminosidade da casca do maracujá-amarelo, tanto nos frutos da colheita 1 , como naqueles da colheita 2 , aumentou progressivamente ao longo do armazenamento, enquanto para os frutos da colheita 3 a luminosidade decresceu, predominantemente durante os nove primeiros dias de armazenamento dos frutos (Figura 1). Os frutos da colheita 1 , colhidos com $1 / 3$ da coloração verde da casca, mostraram evolução na luminosidade, de 45,8, aos 45 daa, até 61,6, aos 51 daa. Porém, aos 54 daa, o valor deste índice reduziu-se, o que pode ter ocorrido devido à intensa redução da massa do fruto e ao aparecimento de manchas escuras, ao final do 
período de estocagem.

Ainda aos 54 daa, quando os frutos da colheita 2 foram analisados, observou-se que a luminosidade destes frutos era menor $(45,4)$ que a luminosidade dos frutos da colheita 1 , armazenados por nove dias $(54,1)$, mostrando que a manutenção dos frutos na planta retarda a evolução da luminosidade da casca. Nos frutos da colheita 2, observou-se que a luminosidade, ao longo do armazenamento, evoluiu de 45,4, aos 54 daa, para 62,3 aos 63 daa. Neste dia, também foi observado que os frutos da colheita 2 apresentaram maior luminosidade da casca do que os frutos da colheita 3 .

Nos frutos da colheita 3, entre os 63 e os 69 daa, observou-se redução na luminosidade da casca, de 52,9 para 38,0, sendo que, aos 72 daa, o valor médio da luminosidade registrado era de 48,2, ou seja, próximo àquele do primeiro dia de avaliação. Estes resultados indicam que, apesar da tendência de diminuição na luminosidade, os frutos desta colheita apresentaram valores deste atributo muito próximos ao longo do armazenamento.

O aumento da luminosidade da casca durante a fase de amadurecimento também é uma tendência verificada em mamão (Hernandez et al., 2006; Pereira et al., 2009) e banana (Hernandez et al., 2006).

O ângulo hue expressa as diferenças na coloração da casca, permitindo visualizar a mudança na cor dos frutos, de verde para amarela (Azzolini et al., 2004). Os resultados do ângulo hue variaram de $119,3^{\circ} \mathrm{h}$, aos 45 daa, na colheita 1 , para $96,4^{\circ} \mathrm{h}$, aos 72 daa, na colheita 3 (Figura 2). Os resultados mostram que a cor da casca evoluiu durante o armazenamento, com uma tendência de mudança do verde para o amarelo, após nove dias de armazenamento, independentemente da época de colheita. Ainda, a manutenção dos frutos na planta retardou a perda da cor verde e o amarelecimento do fruto, verificada pelos valores do ângulo hue, sempre maiores no dia da colheita, em relação aos valores registrados nos frutos com o mesmo tempo de desenvolvimento, porém após o armazenamento.

Nos frutos da colheita 1, observou-se que o ângulo hue variou de 119,3 `h, aos 45 daa, para 104,5 ${ }^{\circ} \mathrm{h}$, aos 54 daa, indicando que a casca se apresentou com cor verde ao longo do armazenamento (Figura 2).

A coloração totalmente amarela foi observada durante o armazenamento dos frutos da colheita 2 e da colheita 3, que atingiram ângulo de cor menor que $100^{\circ} \mathrm{h}$. Nos frutos da colheita 2, os resultados variaram de $115,2^{\circ} \mathrm{h}$, aos 54 daa, para $98,7^{\circ} \mathrm{h}$, aos 63 daa. Nos da colheita 3 , esta diminuição foi de $110,5^{\circ} \mathrm{h}$ para $96,4^{\circ} \mathrm{h}$ (Figura 2).
As alterações na cor da casca do maracujá, durante o amadurecimento, do verde ao amarelo, estão relacionadas aos processos de degradação de pigmentos, tal como a clorofila, bem como a síntese de pigmentos, tais como os carotenoides e flavonoides (Aular et al., 2000; Marchi et al., 2000; Chitarra \& Chitarra, 2005). Tanto a degradação como a síntese dos pigmentos, acima citados, são processos modulados pelo etileno, cuja síntese é estimulada pelo desligamento do maracujá da planta (Shiomi et al., 1996).

A espessura da casca diminuiu ao longo do período de armazenamento (Figura 3), o que também foi verificado na evolução da massa da casca (dados não apresentados). Nos frutos da colheita 1, a diminuição na espessura da casca foi de 9,12 mm para 7,15 mm, enquanto nos da colheita 2 e colheita 3 , esta redução foi de $10,99 \mathrm{~mm}$ para 4,97 mm e de $10,29 \mathrm{~mm}$ para $3,86 \mathrm{~mm}$, respectivamente. Estes resultados indicam que a espessura da casca é fortemente influenciada pelo tempo de desenvolvimento do fruto.

Na Figura 4, são apresentados os resultados do rendimento em suco, sendo observado que, ao longo de todo o período experimental, eles aumentaram. Aos 54 daa, último dia de armazenamento dos frutos da colheita 1 e primeiro da avaliação da colheita 2, os valores médios para o rendimento em suco dos frutos das duas colheitas diferiu estatisticamente. Apesar do menor rendimento em suco, aos 54 daa, nos frutos da colheita 2, as curvas de tendência mostram um pequeno aumentou nesta variável durante o armazenamento dos frutos. Para os frutos da colheita 1, o rendimento do suco aumentou de 30,2 \%, aos 45 daa, para 32,8 \%, aos 54 daa, significando um aumento de cerca de $2 \%$. Já para os frutos da colheita 2, esta variação foi de $27,7 \%$ a 38,5 \%, correspondendo a um aumento de pouco mais de 10 $\%$. Os frutos da colheita 3, aos 63 daa, apresentaram rendimento em suco inferior aos da colheita 2, que foram armazenados, porém o ganho no rendimento em suco desses frutos foi significativo, aumentando de $24,4 \%$ para $48,5 \%$, correspondendo a um aumento de cerca de $99 \%$ durante o armazenamento dos mesmos (Figura 4). Como observado anteriormente, os frutos da colheita 3 apresentaram variação significativa também para a espessura da casca (Figura 3), cuja tendência foi de redução, enquanto para o rendimento de suco observou-se o aumento progressivo em função do tempo após antese. A partir destes dados, pode-se afirmar que, no caso dos frutos da colheita 3 , a redução na espessura da casca pode estar contribuindo para um aumento no rendimento de suco, provavelmente por transferência de água 
da casca para a polpa. Já nos frutos das colheitas 1 e 2, esta relação não foi claramente evidenciada, possivelmente por estes frutos não terem, ainda, atingido o completo desenvolvimento.

De acordo com Nascimento et al. (1999), o rendimento em suco de frutos destinados à industrialização deve ser de, no mínimo, 33 \% da massa total do fruto. Este índice foi atingido apenas nos últimos estádios de armazenamento das colheitas 2 e 3, sendo que o maior rendimento, 38,5 \%, foi atingido aos 63 daa, ou seja, no último dia de armazenamento dos frutos da colheita 2. Este valor foi inferior ao verificado por Aular et al. (2000), que encontram rendimento de $44 \%$ em maracujás com 63 daa.

Considerando que haja transferência de água da casca para a polpa do maracujá, a espessura de casca é uma característica importante, tanto para a indústria de suco concentrado, quanto para o mercado da fruta in natura, por ser inversamente proporcional ao rendimento do suco. Esta relação entre espessura de casca e rendimento de suco, verificada durante o armazenamento dos frutos, principalmente os da colheita 3, também foi observada por Araújo et al. (1974), Gamarra-Rojas \& Medina (1996a) e Nascimento et al. (1999).

Observou-se variação no teor de SS dos frutos ao longo do período experimental em função do desenvolvimento dos mesmo, com aumento de 8,6 ${ }^{\circ}$ Brix, aos 45 daa, para $12,9^{\circ}$ Brix, aos 72 daa (Figura 5). Nos frutos da colheita 1, o teor de SS evoluiu de $8,6^{\circ}$ Brix, aos 45 daa, para $9,7^{\circ}$ Brix, aos 54 daa. Nos da colheita 2, também se observou variação, de 11,1 Brix, aos 54 daa, para 12,1 ${ }^{\circ}$ Brix, aos 63 daa. Nos da colheita 3, esta variação foi menor, de 12,1 ${ }^{\circ}$ Brix, aos 63 daa, para 12,9 ${ }^{\circ}$ Brix, aos 72 daa (Figura 5). Aos 54 daa, entre as colheitas 1 e 2, e aos 63 daa, entre as colheitas 2 e 3, observou-se não haver diferença estatística no teor de SS entre frutos armazenados e recém-colhidos, mostrando que tanto em condições controladas no laboratório como nos frutos que permanecem ligados à plantamãe houve o mesmo padrão de evolução no teor de SS. Porém, como essa evolução no período de armazenamento dos frutos não foi, estatisticamente, significativa, seria prejudicial à qualidade do maracujá a colheita antes dos 54 daa, com perdas no teor de SS dos frutos.

A tendência de aumento no teor de SS durante o desenvolvimento do maracujá-amarelo foi observada também por Pocasangre Enamorado et al. (1995), que verificaram aumento no teor de SS do suco até o $63^{\circ}$ daa; porém, segundo estes autores, o teor de SS destes frutos diminuiu após este período, o que não foi observado aqui nas condições do Norte Fluminense. Os resultados observados neste experimento são comuns para o maracujá-amarelo (Marchi et al., 2000; Vianna-Silva et al., 2005) como à maioria das frutas, que se caracteriza por aumentar o teor de SS no início do amadurecimento, com tendência a diminuir ou estabilizar (Chitarra \& Chitarra, 2005). Resultados diferentes foram encontrados por Shiomi et al. (1995), que verificaram que frutos de maracujazeiro-roxo, colhidos com 40; 60 ou 70 dias após o florescimento (daf), reduziram o teor de SS ao longo do armazenamento, enquanto os frutos colhidos com 80 ou 90 daf não mostraram redução neste atributo. Já Veras et al. (2000), trabalhando em BrasíliaDF, não encontraram diferença significativa entre os teores de SS no suco do maracujá-amarelo colhido em dois estádios de maturação, "de vez”, ou seja, com coloração verde predominando sobre a amarela, e “maduro", com coloração amarela predominando sobre a verde; diga-se de passagem, com teores de SS, 14,67 e $15,21^{\circ}$ Brix, respectivamente, bastante superiores ao verificado neste experimento.

Os teores de acidez titulável (AT) foram bastante variáveis ao longo do período experimental (Figura 6). Sem uma tendência clara, a AT variou de 4,6 \% de ácido cítrico, aos 45 daa, nos frutos da colheita 1, para 5,2 \% de ácido cítrico, aos 72 daa, nos da colheita 3. O armazenamento dos frutos da colheita 1 inibiu o acúmulo de ácidos orgânicos, uma vez que frutos de mesma idade, isto é, 54 daa, porém mantidos na planta, apresentaram teor de AT cerca de $50 \%$ superior. Os frutos colhidos com 54 daa apresentaram redução na AT de 7,2 \% para 3,6 \% de ácido cítrico aos 63 daa, mostrando consumo significativo dos ácidos orgânicos durante o armazenamento dos mesmos. A AT dos frutos colhidos com 63 daa não diferiu daquela dos frutos de mesma idade, armazenados sob condições controladas, indicando que a manutenção do fruto na planta-mãe, neste caso, não influenciou no acúmulo de ácidos. O armazenamento destes frutos resultou em aumento, significativo, na AT, de 3,8 \% para 5,2 \% de ácido cítrico.

A redução do teor de ácidos nos frutos de maracujazeiro-amarelo é um indicativo de evolução do amadurecimento (Vianna-Silva et al., 2005; Vianna-Silva et al., 2008). A utilização dos ácidos orgânicos como substrato respiratório (Lam, 1990; Alique et al., 2005) é função da disponibilidade de outros substratos mais simples, como carboidratos solúveis (glicose, frutose e sacarose), e de reserva, como o amido. No maracujá-amarelo, os carboidratos solúveis representam em média 17,3\% da composição da polpa do fruto (Chavan \& Kadam, 1995), sendo esses formados por glicose $(32,4 \%)$, frutose, $(29,4 \%)$ 
e sacarose, (38,1\%) (Durigan et al., 2004), enquanto a concentração de amido na polpa está entre 1,0 e 3,7\% (Chavan \& Kadam, 1995). Como nos frutos da colheita 1 a disponibilidade de substratos mais simples estava baixa, verificado pelo teor de SS (Figura 5), pode ter havido um consumo dos ácidos orgânicos pelo processo respiratório, principalmente a partir do $48^{\circ}$ daa. O processo respiratório, provavelmente, também deve ser o responsável pela forte redução na AT entre o $54^{\circ}$ e o $63^{\circ}$ daa. Nestes frutos da colheita 2 , ainda que a disponibilidade de açúcares solúveis estivesse mais alta, como indicado pelo teor de SS, a atividade respiratória dos frutos estava alta, uma vez que o pico respiratório do maracujá colhido nesta região foi verificado no $56^{\circ}$ daa (Vianna-Silva, 2008).

Em fase mais avançada do desenvolvimento do fruto, a senescência tem como característica a síntese de ácidos orgânicos, alguns voláteis, que são responsáveis pelo cheiro característico do maracujá, como outros não voláteis (Chavan \& Kadam, 1995). É provável que os frutos colhidos aos 63 daa rapidamente atingiram a fase de senescência, o que justificaria o aumento na AT, mesmo que estes ainda apresentassem coloração verde predominante (Figura
2), como discutido anteriormente, pela manutenção dos mesmos na planta-mãe.

O padrão observado para a AT neste trabalho difere daquele verificado por outros autores. ViannaSilva et al. (2005 e 2008) verificaram um aumento seguido de redução na variação da AT do suco de frutos de maracujazeiro-amarelo, colhidos na mesma região, com tempo de desenvolvimento igual àquele da colheita 3, isto é, entre 63 e 72 daa, enquanto Marchi et al. (2000) observaram redução no ter da AT no final do amadurecimento do maracujá-amarelo.

Os níveis de rendimento em suco e AT verificados neste trabalho, em sua maioria, estão próximos ao sugerido para o maracujá-amarelo, que é de 30 \% a $40 \%$ e 4,9 \% de ácido cítrico, respectivamente (Durigan et al., 2004). Os resultados mostram que, em todas as colheitas, os frutos já haviam ultrapassado a maturação fisiológica, sendo aptos a completar a sua ontogenia mesmo desligados da planta-mâe. Vale destacar o baixo teor de SS encontrado, mesmo nos frutos colhidos com 63 daa, inferior ao padrão sugerido para a espécie, que é de 14,9 \% a 18,6\%, segundo Durigan et al. (2004).

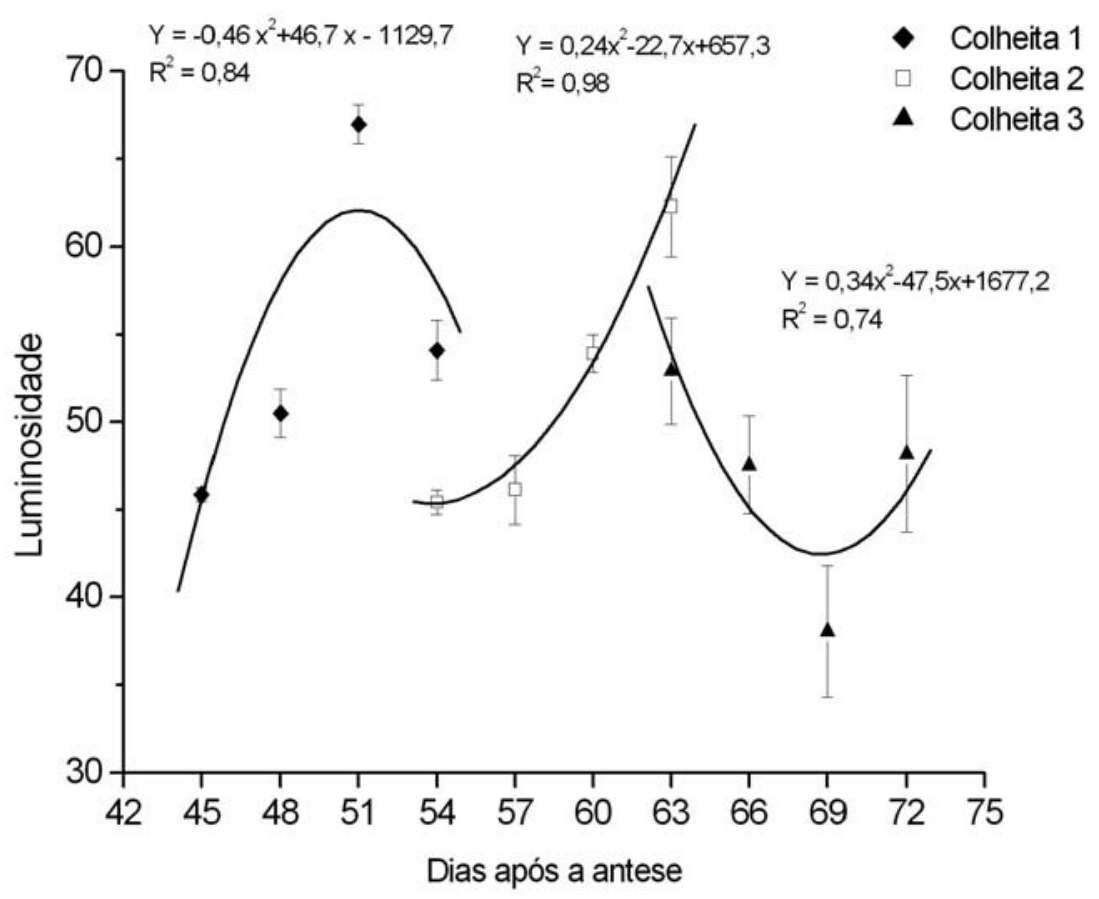

FIGURA 1 - Luminosidade da casca dos frutos de maracujazeiro-amarelo colhidos em três épocas e armazenados por 9 dias, a $23^{\circ} \mathrm{C}$ e $85 \%$ UR. 


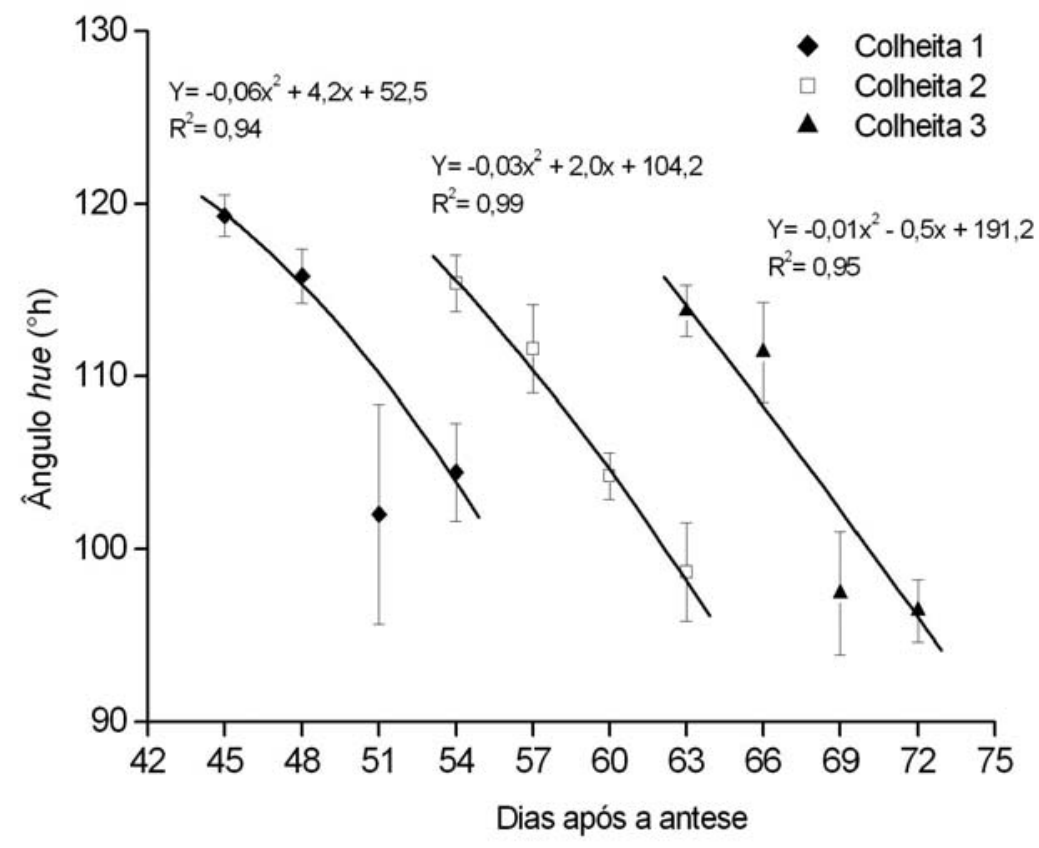

FIGURA 2 - Ângulo hue da casca dos frutos de maracujazeiro-amarelo colhidos em três épocas e armazenados por 9 dias, a $23^{\circ} \mathrm{C}$ e $85 \%$ UR.

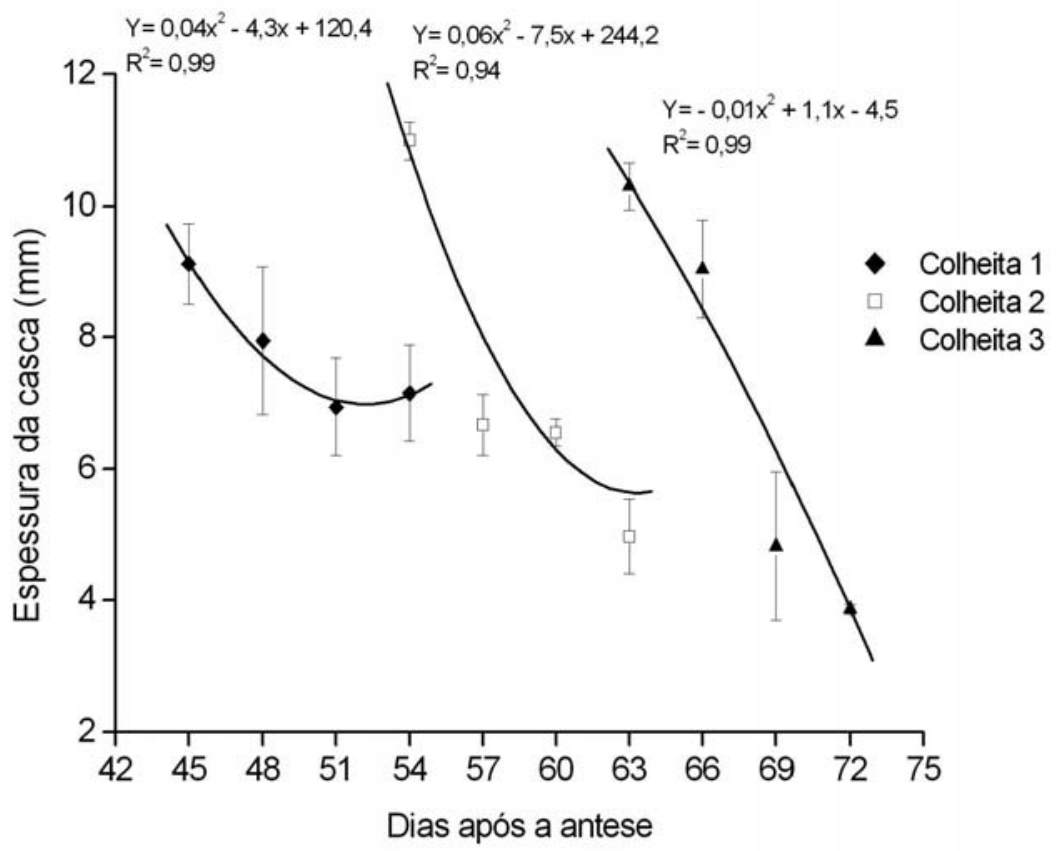

FIGURA 3- Espessura da casca dos frutos de maracujazeiro-amarelo colhidos em três épocas e armazenados por 9 dias, a $23^{\circ} \mathrm{C}$ e $85 \%$ UR. 


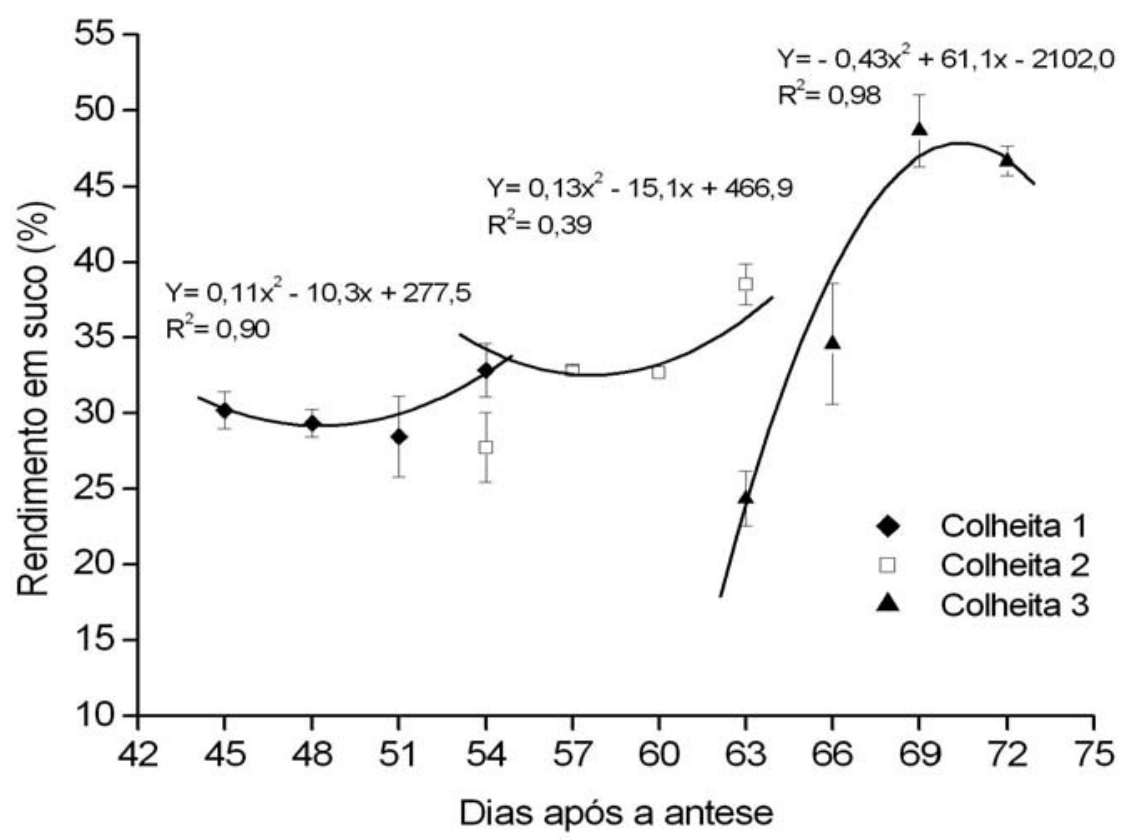

FIGURA 4 - Rendimento em suco (\%) de frutos de maracujazeiro-amarelo colhidos em três épocas e armazenados por 9 dias, a $23^{\circ} \mathrm{C}$ e $85 \%$ UR.

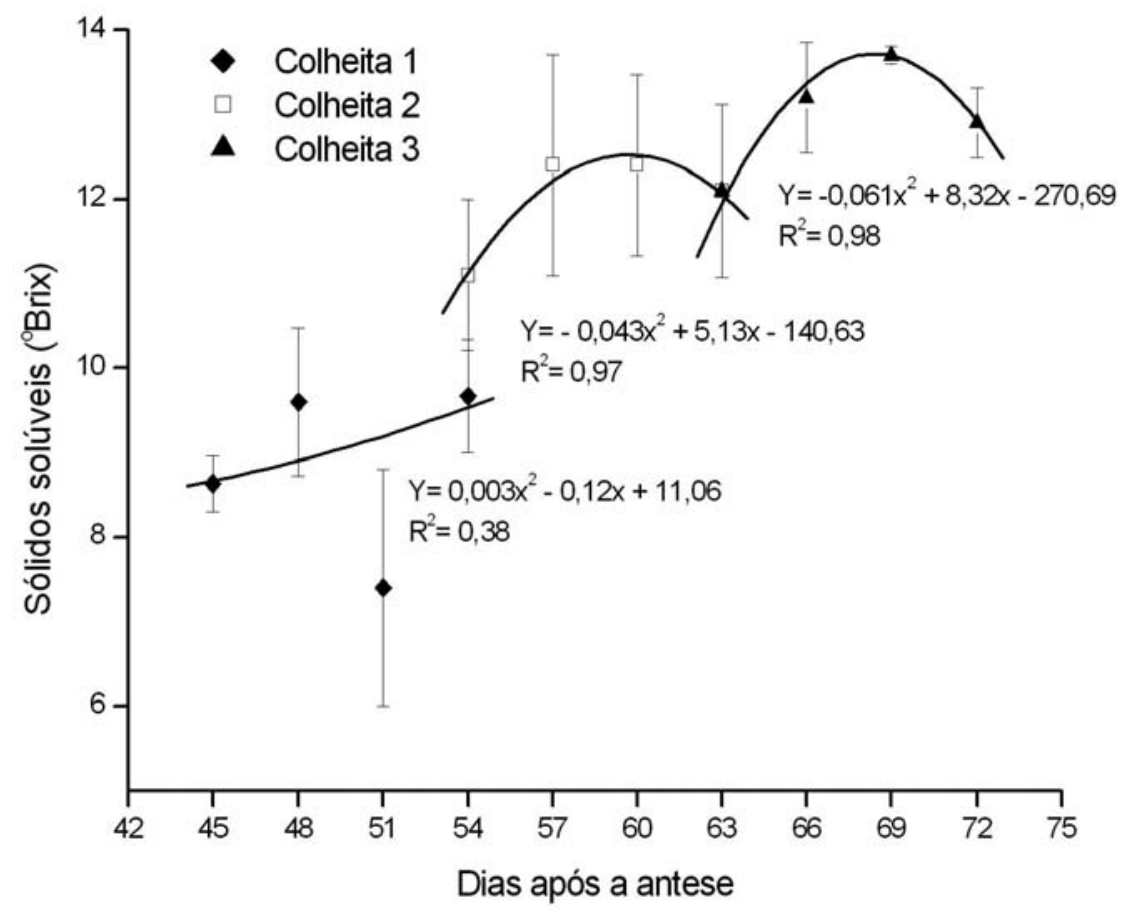

FIGURA 5 - Teor de sólidos solúveis no suco de frutros de maracujazeiro-amarelo colhidos em três épocas e armazenados por 9 dias, a $23^{\circ} \mathrm{C}$ e $85 \%$ UR. 


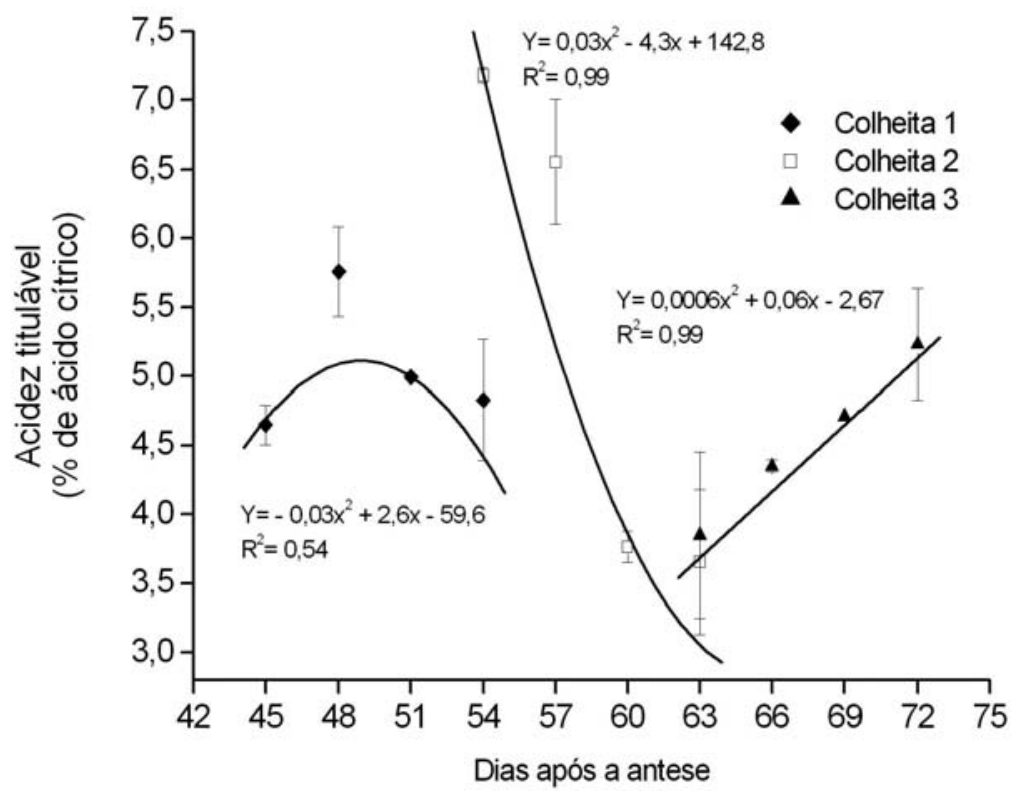

FIGURA 6 - Teor de acidez titulável no suco de frutos de maracujazeiro-amarelo colhidos em três épocas e armazenados por 9 dias, a 23 C e 85 \% UR.

\section{CONCLUSÃO}

1-Frutos de maracujazeiro-amarelo produzidos na região norte do Estado do Rio de Janeiro, colhidos a partir de 45 daa, já atingiram a maturidade fisiológica. Porém, o ponto ideal de colheita foi aos 63 daa, quando se verifica o maior rendimento em suco.

2-Verificou-se, também, que durante a fase de amadurecimento do maracujá, o destacamento do fruto da planta estimula a mudança de cor da casca do verde para o amarelo.

\section{REFERÊNCIAS}

AGUIAR, D.R.; SANTOS, C.C.F.S. Importância econômica e mercado. In: BRUCKNER, C.H.; PICANÇO, M.C. Maracujá: tecnologia de produção, pós-colheita, agroindústria, mercado. Porto Alegre: Cinco continentes, 2001. p. 9-31.

ALIQUE, R.; ZAMORANO, J.P.; MARTINEZ, M.A.; ALONSO, J. Effect of heat and cold treatments on respiratory metabolism and shelf-life of sweet cherry, type picota cv. “Ambrunes”. Postharvest Biology and Technology, Amsterdam, v. 35. p.153165, 2005.
ARJONA, H.E.; MATTA, F.B.; JAMES, O.G. Temperature and storage time affect quality of passion fruit. Hortsciense, Alexandria, v. 27, n. 7, p. 809-810,1992.

ARAÚJO, C.M.; GAVA, A.J.; ROBBS, G.P.; NEVES, J.F.; MAIA, P.C. Características industriais do maracujá (Passiflora edulis var. flavicarpa) e maturação do fruto. Pesquisa Agropecuária Brasileira, Brasília, v. 9, p. 65-69, 1974.

AULAR, J.; RUGGIERO, C.; DURIGAN, J.F. Influência da idade na colheita sobre as características dos frutos e do suco de maracujá-amarelo. Revista Brasileira de Fruticultura, Jaboticabal, v.22, p.6-8, 2000. n.especial

AZZOLINI, M.; JACOMINO, A.P.; BRON, I.U. Índices para avaliar qualidade pós-colheita de goiabas em diferentes estádios de maturação. Pesquisa Agropecuária Brasileira, Brasília, v.39, n.2, p.139145, 2004.

BERNACCI, L.C.; SOARES-SCOTT, M.D.; JUNQUEIRA, N.T.V.; PASSOS, I.R.S.; MELETTI, L.M.M. Passiflora edulis Sims: the correct taxonomic way to cite the yellow passion fruit (and of others colors). Revista Brasileira de Fruticultura, Jaboticabal, v.30, n.2, p. 566-576, 2008. 
CHAVAN, U.D.; KADAM, S.S. PASSION FRUIT. IN. SALUNKHE, D.K.; KADAM, S.S. Handbook of fruit science and technology. production, composition, storage, and processing. New York: Marcel Dekker, 1995. p. 445-454.

CHITARRA, M.L.F.; CHITARRA, A.B. Pós-colheita de frutos e hortaliças: fisiologia e manuseio, Lavras: UFLA, 2005. 785p.

DURIGAN, J.F. Colheita e conservação pós-colheita. In: RUGGIERO, C. Maracujá do plantio à colheita. Jaboticabal: Funep, 1998. 388p.

DURIGAN, J.F.; SIGRIST, J.M.M.; ALVES, R.E.; FILGUEIRAS, H.A.C.; VIEIRA, G. Qualidade e tecnologia pós-colheita do maracujá. In: LIMA, A.A.; CUNHA, M.A.P. Maracujá: produção e qualidade na passicultura. Cruz das Almas: Embrapa, 2004. p. 283-303.

GAMARRA-ROJAS, G.; MEDINA, V.M. Mudanças bioquímicas do suco do maracujá-amarelo em função da idade do fruto. Revista Brasileira de Fruticultura, Jaboticabal, v.18, n.1, p. 75-83, 1996.

HERNÁNDEZ, Y.; LOBO, M.G.; GONZÁLEZ, M.. Determination of vitamin C in tropical fruits: a comparative evaluation of methods. Food Chemistry, Berkshire, v. 96, p. 654-664, 2006.

KLUGE, R.A.; NACHTIGAL, J.C.; FACHINELLO, J.C.; BILHALVA, A.B. Fisiologia e manejo póscolheita de frutas de clima temperado. 2.ed. Campinas: Livraria e Editora Rural, 2002. 214p.

LAM, P.F. Respiration rate, ethylene production and skin color change of papaya at different temperatures. Acta Horticulturae, Wageningen, v. 269, p. 257-266, 1990.

MARCHI, R.; MONTEIRO. M.; BENATO, E.A.; SILVA, C.A.R. Uso da cor da casca como indicador de qualidade do maracujá amarelo (Passiflora edulis Sims. f. flavicarpa Deg.) destinado à industrialização. Ciência e Tecnologia de Alimentos, Campinas, v. 20. n. 3. 2000.

McGUIRE, R.G. Reporting of objective color measurements. HortScience, Alexandria, v.27, p.12541255, 1992.
NASCIMENTO, T.B.; RAMOS, J.D.; MENEZES, J.B. Características físicas do maracujá-amarelo produzido em diferentes épocas. Pesquisa Agropecuária Brasileira, Brasília, v. 34. n. 12. p. 23532358, 1999.

PEREIRA, T.; ALMEIDA, P.S.G.; AZEVEDO, I.G.; CUNHA, M.; OLIVEIRA, J.G.; SILVA, M.G.; VARGAS, H. Gas diffusion in 'Golden' papaya fruit at different maturity stages. Postharvest Biology and Technology, Amsterdam, v. 54. p.123-130, 2009.

POCASANGRE ENAMORADO, H.E.; FINGER, F.L.; BARROS, R.S.; PUSCHMANN, R. Development and ripening of yellow passion fruit. Journal of Horticultural Science, Ashford, v. 70, n. 4, p. 573-576, 1995.

SHIOMI, S.; KUBO, Y.; WAMOCHO, L.S.; KOAZE, H.; NAKAMURA, R.; INABA, A. Postharvest ripening and ethylene biosynthesis in purple passion fruit. Postharvest Biology and Technology, Amsterdam, n. 8, p.199-207, 1996.

SHIOMI, S.; WAMOCHO, L.S.; AGONG, S.G.. Ripening characteristics of purple passion fruit on and off the vine. Postharvest Biology and Technology, Amsterdam, n. 7, p.161-170. 1995.

VERAS, M.C.M.; PINTO, A.C.Q.; MENESES, J.B. Influência da época de produção e dos estádios de maturação nos maracujá-doce e ácido nas condições de cerrado. Pesquisa Agropecuária Brasileira, Brasília, v.35. n. 5. p. 959-966,2000.

VIANNA-SILVA, T. Fisiologia do desenvolvimento dos frutos do maracujazeiro-amarelo e maracujazeiro-doce. Campos dos Goytacazes, 2008. $156 \mathrm{f}$. Tese (Doutorado em Produção Vegetal) - Universidade Estadual do Norte Fluminense Darcy Ribeiro, Campos dos Goytacazes, 2008.

VIANNA-SILVA, T.; RESENDE, E.D.; VIANA, A.P.; ROSA, R.C.C.; PEREIRA, S.M.F.; ALMEIDA CARLOS, L.; VITORAZI, L. Influência dos estádios de maturação na qualidade do suco do maracujáamarelo. Revista Brasileira de Fruticultura, Jaboticabal, v. 27, n. 3. p. 472-475, 2005. 
VIANNA-SILVA, T.; RESENDE, E.D.; VIANA, A.P.; PEREIRA, S.M.F.; ALMEIDA CARLOS, L.; VITORAZI, L. Qualidade do suco de maracujáamarelo em diferentes épocas de colheita. Ciência e Tecnologia de Alimentos, Campinas, v. 28, n. 3. p. 545-550, 2008.

WATADA, A.E.; HERNER, R.C.; KADER, A.A.; ROMANI, R.J.; STABY, G.L. Terminology for the description of developmental stages of horticultural crops. HortScience, Alexandria, v. 19, n. 1, p.2021, 1984.
ZENEBON, O.; PASCUET, N.S.; TIGLEA, P. (Coord.). Métodos físico-químicos para análise de alimentos. 4. ed. São Paulo: Instituto Adolfo Lutz, Secretaria de Estado da Saúde, 2008. 1020 p. 